\title{
Antioxidant supplementation decreases the cell death rate in the prostatic stromal tissue of long-term castrated rats
}

\author{
Guilherme Fartes, Fábio Lorenzetti, Larissa Beloti Salvador, Valdemar Ortiz, Miriam Dambros
}

Federal University of São Paulo, Sao Paulo, Brazil

\section{ABSTRACT}

Objective: The purpose of this study was to compare the effects of castration on cell death rate of the adult rat prostates and to evaluate the benefic action of alpha tocopherol supplementation to avoid apoptosis post-orchiectomy.

Material and Methods: Thirty male Wistar rats weighing 250-300g were divided into three groups: group I - they were subjected to bilateral orchiectomy and sacrificed eight weeks after the procedure; group II - subjected to bilateral orchiectomy and alpha-tocopherol supplementation for four weeks preceding the procedure; and group III - subjected to bilateral orchiectomy and alpha-tocopherol supplementation for four weeks preceding the procedure and for eight weeks afterwards. At the end of the experiment, the prostatectomy was performed in all rats. The presence of oxidative stress was determined by assaying the blood level of 8-isoprostane and the occurrence of apoptosis was evaluated by identification of active caspase- 3 through immunohistochemical analysis.

Results: The statistic analysis of active caspase- 3 showed that in the long-term castrated group the detection was higher than in groups were the alpha-tocopherol was supplemented ( $p=0.007)$. Analysis of 8 -isoprostane levels showed higher concentrations of reactive oxygen species in group I compared to other groups $(\mathrm{p}<0.05)$. Groups II and III presented active caspase-3 lower than in group I $(\mathrm{p}<0.05)$.

Conclusion: Our exploratory analyses demonstrate a method to study the aging process and its influence on oxidative stress of prostatic tissue and cells death rate. Based on our results we can suggest that alpha tocopherol supplementation can decrease the apoptotic process as well as the oxidative stress levels induced by androgen deprivation of the prostate gland.

\section{ARTICLE INFO}

\section{Key words:}

Prostate; Testosterone;

Oxidative Stress;

alpha-Tocopherol; Apoptosis

Int Braz J Urol. 2012; 38: 419-25

Submitted for publication:

April 11, 2011

Accepted after revision:

October 13, 2011

\section{INTRODUCTION}

During the male aging process, prostate growth occurs in the form of benign prostatic hyperplasia and prostatic carcinoma. The androgens have a central role in regulating the growth of the prostate with the ability to stimulate pro- liferation and inhibit cell death rate. The androgen ablation by castration leads to rapid cell death, mainly in the ventral prostate lobe of rats, through apoptosis. Defects on the mechanism of programmed cell death have great participa- 
tion in the pathogenesis of several proliferative changes and attempts to activate apoptosis represent a possibility of therapeutic approach (1).

Androgens may be involved in the epithelial stroma interaction. In mature prostate, androgens are known to cause several changes in prostatic epithelium through androgen receptors located in the stroma. Immunocytochemical studies have shown that prostatic smooth muscle cells are uniformly androgen receptorpositive. This fact indicates that smooth muscle located in prostatic stroma may be an important target for androgen action and able to regulate the expression of prostate growth factors (2).

Apoptosis is an important physiological process associated with aging $(3,4)$. It is defined by a set of morphological and biochemical changes in different cellular levels (5), and the result is the elimination of unwanted cells, leaving the surrounding tissue intact. In relation to aging, apoptosis has a primary negative effect, by destruction of essential and often irreplaceable cells. But it also eliminates non-functioning cells and protects the organs against cancer or hypertrophy (6).

Reactive oxygen species (ROS) act probably on nucleic acids, causing cellular damage by reaction with membrane lipids and proteins, and modulate the expression of some genes related to cellular differentiation and proliferation. Due to these facts, they may trigger the signaling routes that lead to cell apoptosis (7). It has been suggested an imbalance between apoptosis and cell proliferation that results in the development of the HPB (benign prostatic hyperplasia). Zang et al. (8) demonstrated close relationship between a high rate of proliferation of stromal region and a high rate of apoptosis in glandular epithelium in BPH. Therefore, the development of BPH may be associated with stromal growth, through the proliferation of stromal cells mesenchyma active, and the epithelial growth, due to reduction in cellular apoptosis.

Recent experimental study showed the beneficial action of vitamin $E$ in reducing the activation of the intrinsic pathway of apoptosis and cell death rate induced by moderate oxidative stress (9). It can react directly with a variety of oxi-radicals such as superoxide, the hydroxyl and also with the singlet oxygen (10). Bell (11) showed the protection obtained by vitamin $\mathrm{E}$ against oxidative damage of unsaturated fatty acids tissue.

Considering the exposed above, we aimed to study the occurrence of apoptosis in prostatic stroma in the presence of low levels of testosterone, yet assessing the beneficial action of alpha-tocopherol to prevent the state of oxidative stress induced by orchiectomy.

\section{MATERIALS AND METHODS}

\section{Animals and Diet}

Thirty male Wistar rats, 3 months old, were used in these experiments. Rats were housed at the university's animal facility on a 12-hour light/ 12-hour dark cycle and allowed access to food and water ad libitum.

\section{Grouping of animals}

The animals were divided into 3 groups of 10 animals each: Group I: the rats were subjected to bilateral orchiectomy. Group II: subjected to bilateral orchiectomy and received supplementation with alpha-tocopherol for four weeks preceding the castration procedure. Group III: subjected to bilateral orchiectomy, with supplementation of alpha-tocopherol for four weeks preceding the procedure and for eight weeks afterwards. After 8 weeks of the beginning of the experimental protocol, the animals were sacrified and venous blood was collected from the dorsal vein of the tail, in order to assay the 8-isoprostane and testosterone levels. The groups II and III received alpha-tocopherol dissolved in $0.1 \mathrm{~mL}$ of sesame oil (Galênica, SP - Brazil) at a dosage of 1000 $\mathrm{UI} / \mathrm{kg} /$ week intramuscularly. The prostate was quickly removed and formalin-fixed and paraffin-embedded and submitted to histological and immunofluorescence studies.

\footnotetext{
Alpha-tocopherol assay

Alpha-tocopherol was quantified by highperformance chromatography, using fluorescence with an excitation wavelength of $292 \mathrm{~nm}$ and an emission wavelength of $340 \mathrm{~nm}$. The values were expressed in $\mathrm{ng} / \mathrm{mg}$.
} 


\section{Measurement of testosterone}

Blood was collected from the dorsal vein of the tail, in order to assay total serum testosterone by competitive radioimmunoassay (testosterone direct radioimmunoassay kit, Immunotech, Brazil, cat \# 1119).

\section{Oxidative Products}

Enzimatic immune assay of oxidatively modified product isoprostane 8-epi-PGF2 $\alpha$ was performed, as previously reported (14). Briefly, the concentration of 8-isoprostane in the samples was measured using a commercial enzymatic immunoassay kit (Cayman Chemical). The assay was based on competition between the 8-isoprostane present in the sample and 8-isoprostane conjugated with acetylcholinesterase by a limited concentration of anti-8-isoprostane antibody. The new complex formed between 8-isoprostane conjugated with antibody combined with another antibody was detected by means of a reaction with 5.5 -dithiobis (2-nitrobenzoic acid)-DTNB- (absorbed at 405 $\mathrm{nm}$ ), which was hydrolyzed by the acetylcholinesterase of the conjugate. The concentration of 8-isoprostane was determined by interpolation on a standard curve. The detection limits were from 6 to $500 \mathrm{pg} / \mathrm{mL}$. The samples were diluted by a factor of four and all values obtained were within the detection limits. Microtiter plates were scanned by means of a computer software that allowed wavelength adjustment and plate reading (EL x 800 instruments). The results were expressed in $\mathrm{pg} / \mathrm{mL}$.

\section{Determination of apoptosis}

To prepare tissue sections for immunostaining it was used paraffın clearing of the slides placing them in fume hood, overnight, at $60^{\circ} \mathrm{C}$. After that, the paraffin was cleared with xylene for 30 minutes and the slides were moved to a fresh dish of xylene for an additional 30 minutes. The slides were rinsed twice for 10 minutes in 80\% alcohol (18:1:1 100\% ethanol: 100\% methanol: $100 \%$ isopropanol). The slides were rinsed five times with fresh deionized water.

The Antigen Retrieval Method was made placing slides face-up in incubation tray and covering each section with 1\% SDS in PBS $(137 \mathrm{mM}$
$\mathrm{NaCl}, 2.7 \mathrm{mM} \mathrm{KCl}, 4.3 \mathrm{mM} \mathrm{Na} 2 \mathrm{HPO} 4$, and $1.47 \mathrm{mM}$ $\mathrm{KH} 2 \mathrm{P04}$ ). After that, they were incubated for five minutes at room temperature, followed by three five minute washes with phosphate buffered saline (PBS). Then, the slides were immersed in blocking buffer 1 (3\% Molico ${ }^{\circledR}$, diluted 1:10 in PBS) - 3g non-fatted cow milk (Molico ${ }^{\circledR}$ ): 100 mL PBS. After that, they were incubated overnight at $4^{\circ} \mathrm{C}$.

To prepare the incubation with primary antibodies (rabbit anti-caspase 3) the sections were covered with blocking buffer 2 (3\% Moli$\mathrm{co}^{\circledR}$, diluted 1:10 in PBS, plus $200 \mu \mathrm{L}$ Tween). Tissue sections were covered with primary antibody (rabbit anti-caspase-3 - C8487) diluted in 1:500 blocking buffer 2 and incubated at 370C for one hour. The excess liquid was blotted from slides and rinsed three times in PBS for five minutes each wash. To prepare the incubation with secondary antibodies (chicken anti-rabbit IgG) the tissue sections were covered with secondary antibody (chicken anti-rabbit IgG - F0382) diluted 1:40 in blocking buffer 2 and incubated at 370C for one hour. The excess liquid was blotted from slides and rinsed three times in PBS for five minutes each wash.

To prepare the counterstaining and visualization (nuclear staining) the slides were immersed for 15 minutes in $100 \mu \mathrm{L}$ solution of propidium iodide diluted 1:10 in PBS. The slides were rinsed in PBS for five minutes. The coverslip was placed for visualization by fluorescence microscopy. The volumetric density of the distribution of active caspase- 3 was analyzed by overlaying the M-42 grid system on the computed morphological image of the slide.

\section{Statistical Analysis}

In all data the criterion for significance was $\mathrm{p}<0.05$. Futhermore, for 8 -epi-PGF $2 \alpha$ and testosterone statistical analysis, the nonparametric Kruskal-Wallis test was used, with the Bonferroni correction test. The results were considered statistically significant when $p<0.05$. The data obtained from caspase- 3 were analyzed using the SPSS 12.0 statistics software (SPSS Inc., USA) and were expressed as mean \pm standard deviation. The nonparametric Newman-Keuls test for multiple 
comparisons was used to assess the differences between the independent samples.

\section{RESULTS}

\section{Alpha-tocopherol}

The concentration of alpha-tocopherol was $0.69 \mathrm{ng} / \mathrm{mg}$ in group II; $1.73 \mathrm{ng} / \mathrm{mg}$ in group II and $1.83 \mathrm{ng} / \mathrm{mg}$ in group III. The comparative analysis showed that the values in groups II and III were statistically greater than those of groups I and II $(\mathrm{p}=0.003)$.

\section{Testosterone measurements}

The serum testosterone concentrations immediately before sacrifice of the animals of the orchiectomized groups with or without alpha-tocopherol replacement were lower than $20 \mathrm{pg} / \mathrm{mL}$, the lower limit of sensitivity of the method applied. This demonstrated the presence of a significant hormone deficit at the time of the sacrifice of these animals.

\section{Marker of Oxidative Stress}

Analysis of the 8-isoprostane levels demonstrated statistically higher values $(p<0.0003)$ in group I ( $5.1 \mathrm{pg} / \mathrm{mL})$, i.e. among the orchiectomized rats without alpha-tocopherol replacement, in relation to groups II $(2.4 \mathrm{pg} / \mathrm{mL})$ and III $(2.6 \mathrm{pg} / \mathrm{mL})$.

\section{Caspase-3}

The statistical analyses showed that the volumetric density of active caspase- 3 was greater in the orchiectomized group without alpha-tocopherol supplementation (32.4\%) than in the other groups (group II, 18.8\%; group III, $18.6 \%)(p=0.007)$. In addition, there was no statistically significant difference between the group that received alpha-tocopherol supplementation before orchiectomy and the group that received it both before and after orchiectomy $(\mathrm{p}=0.55)$ (Table-1).

The Figures 1-3 show the immunohistochemical method used for the detection of active caspase 3 on the prostatic tissue in the three different groups. The positive reactions are seen in green and the nucleus in red.
Table 1 - Quantitative analysis of active Caspase-3 in tissue.

\begin{tabular}{lc}
\hline & $\%$ active caspase-3 in tissue \\
\hline GROUP I & $32,4^{\star}$ \\
GROUP II & 18,8 \\
GROUP III & 18,6 \\
\end{tabular}

${ }^{*} p<0,05$

Figure 1 - Group I. Microscopic fluorescence immunohistochemistry for the detection of active caspase-3. Increase 10x.

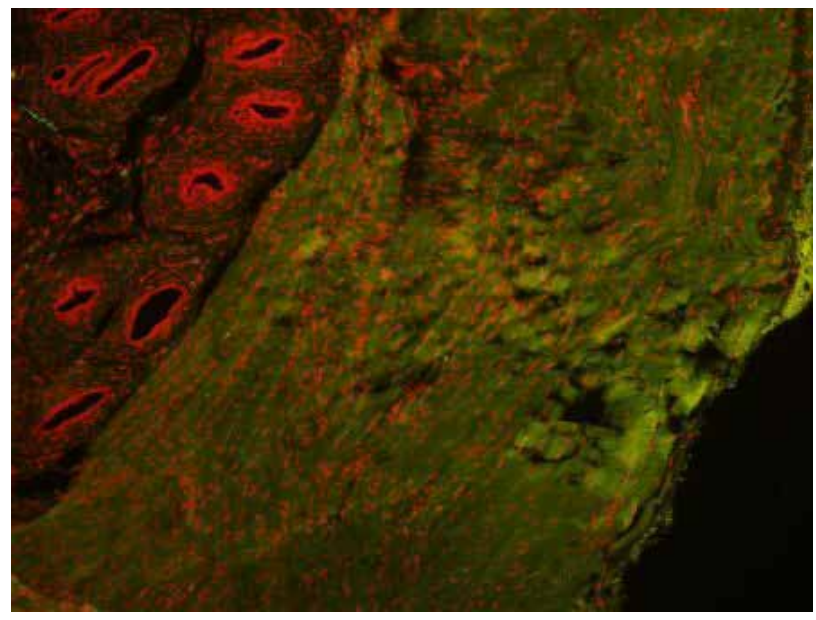

Figure 2 - Group II. Microscopic fluorescence immunohistochemistry for the detection of active caspase-3. Increase 10x.

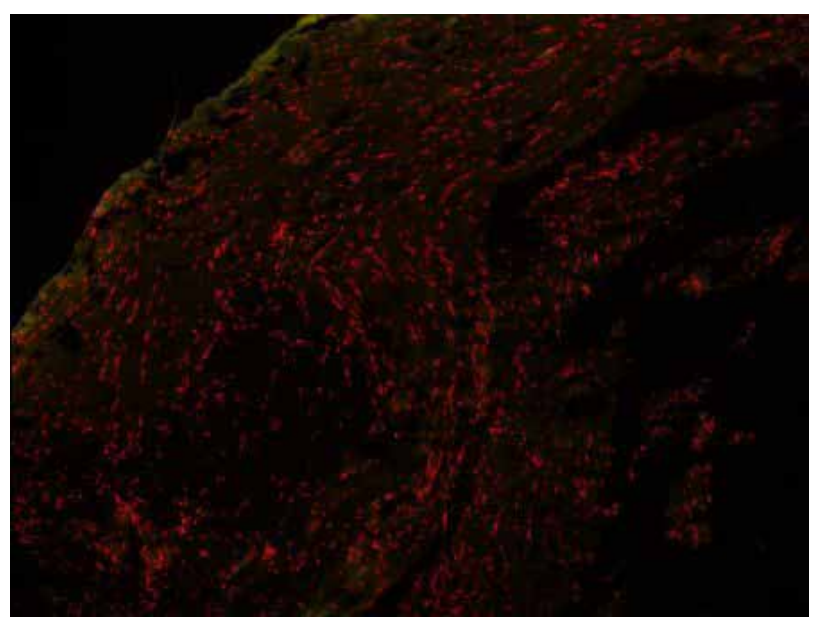


Figure 3 - Group III. Microscopic fluorescence immunohistochemistry for the detection of active caspase-3. Increase 10x.

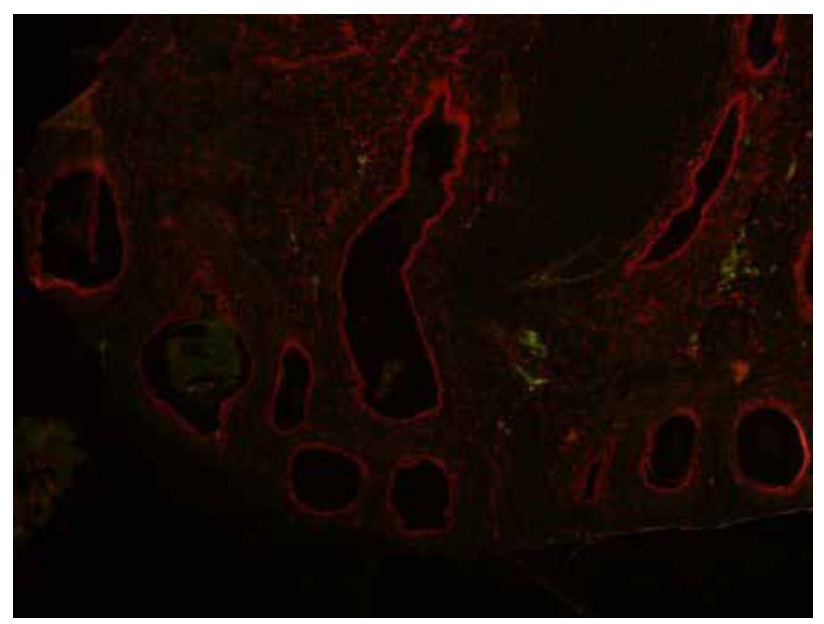

\section{DISCUSSION}

In the mid-1950s, the theory of free radicals to explain the aging process was proposed, speculating that endogenous oxygen radicals were produced in cells and resulted in a pattern of cumulative damage. Only a decade later, with the identification of the enzyme superoxide dismutase (SOD), responsible for the conversion of superoxide radical to hydrogen peroxide, there was scientific support for that hypothesis (12).

Oxidative stress, or oxidative damage, is present when there is an imbalance between the natural antioxidants and reactive oxygen species. With aging, there is a decrease of antioxidant mechanisms, resulting in prevalent cellular damage caused by free radicals (13).

However, there is increasing evidence of the role of oxidizing agents specific in signaling molecules in both physiological and pathophysiological conditions (12).

The generation of reactive oxygen species is related to the maintenance of homeostasis, as an example, in combating infectious processes through the generation of ROS by phagocytic cells and regulation of the proliferative response. Regardless of how or where they are produced, increasing intracellular levels of ROS has two important effects: damage of various cellular components and induction of activation of spe- cific signaling chains; both effects can influence several processes related to the process of aging and development of associated diseases (12).

There is evidence showing that the aging process contributes to the accumulation of oxidative damage in different cells and molecules (14).

In this study, a dosage of 8-isoprostane was used as a marker of oxidative stress to check the presence of oxidative stress after eight weeks of bilateral orchiectomy. This marker has been used in animals and humans. In general, the isoprostanes are present in blood in nanomolar concentrations and are increased in many pathological conditions, such as renal and myocardial ischemia, pulmonary hypertension, hypercholesterolemia and neurogenic detrusor hyperactivity $(15,16)$.

Corroborating the literature, we demonstrated high levels of 8-isoprostane serum in rats undergoing orchiectomy, without replacement of alpha-tocopherol (group I), reflecting increased oxidative stress associated with hypoandrogenism. A statistically significant reduction was observed in the estimation of 8-isoprostane after supplementation of alpha-tocopherol in both groups that received supplementation, demonstrating the protective effect of alpha-tocopherol to reduce the serum levels of oxidative stress, and its action, especially by preventing the generation of radicals.

Antioxidants are substances that when present in small concentrations, compared with those oxidizable substrate, significantly delay or inhibit the oxidation of the substrate and may act at different levels of the oxidative sequence.

The use of alpha-tocopherol was based on several studies that demonstrated its beneficial action in various urological diseases $(17,18)$; moreover, it is one of the most powerful and effective exogenous antioxidants, preventing the peroxidation and avoiding the effects of oxidative stress $(19,20)$. We chose the use of alpha-tocopherol because of its well established pharmacokinetics, which assisted the determination of the dose to be employed oral or parenterally (20).

There are reports in the literature of the protection against damage related to aging by using vitamin E in Sprague-Dawley rats with removal of 8-isoprostane and reduction of oxidative damage (21). 
Apoptosis is an important physiological process that is related to aging $(3,4)$. It is defined as a set of biochemical and morphological changes in different cellular levels, resulting in the elimination of unwanted cells (5). However, with aging, apoptosis has a negative effect since it destroys vital and often irreplaceable cells (6).

Among the various ways of identifying the process of apoptosis, we chose the detection of active caspase-3, since the caspase enzymes are involved in various stages of apoptosis, from the initial signal to the final lysis of cellular components. The active caspase- 3 is the final effector of cell lysis, so we decided to use it as a marker of irreversible apoptosis.

The prostatic overgrowth in the form of $\mathrm{BPH}$ or CaP observed during aging is credited to an imbalance between proliferation and cell death rates. Recent studies have indicated not only the rate of cell proliferation, but also the rate of cell death associated to tumor size. Previous studies have demonstrated the induction of apoptosis in prostate of rats through the male hormone decline induced by aging or by orchiectomy $(1,22,23)$. The castration causes loss of weight of the gland and reduction of cell size in all lobes, but the apoptosis in response to androgen withdrawal occurs predominantly in the ventral lobe. The castration has little effect on DNA content or rate of apoptosis in dorsal lobes, lateral and anterior. Although the apoptotic index was lower in dorsal, lateral and anterior lobes compared with the ventral lobe, the percentage of apoptotic cells observed in the 4 prostate lobes were significantly reduced with age (1).

This study demonstrated a statistically significant difference between the levels of active caspase- 3 in animals of the groups that received alpha-tocopherol supplementation (groups II and III) in relation to the group without supplementation, that was higher in those without supplementation. It was observed that in groups with supplementation, the dosage of 8-isoprostane was significantly lower in the castrated group without the use of antioxidant, suggesting that the serum oxidative stress, detected by 8-isoprostane, has a role in apoptosis of castrated rats. These findings demonstrate that the probable pathway of apoptosis induced by androgen ablation is the oxidative stress, since the use of vitamin E reduced both the dosage of 8-isoprostane and quantification of active caspase- 3 .

The findings demonstrated in this study show that oxidative stress may have an important role in the process of apoptosis in prostate stroma of rats, due to low levels of testosterone (hypoandrogenism). It was found that supplementation of alpha-tocopherol after bilateral orchiectomy decreased the apoptotic index, but it is necessary to emphasize that this work was designed to evaluate animals submitted to orchiectomy as a cause of aging. This study will follow the line of research that intents to clarify the factors involved in the development of benign prostatic hyperplasia and a possible better and less invasive therapeutic approach.

\section{CONFLICT OF INTEREST}

\section{None declared.}

\section{REFERENCES}

1. Banerjee S, Banerjee PP, Brown TR: Castration-induced apoptotic cell death in the Brown Norway rat prostate decreases as a function of age. Endocrinology. 2000; 141: 821-32.

2. Niu YJ, Ma TX, Zhang J, Xu Y, Han RF, Sun G: Androgen and prostatic stroma. Asian J Androl. 2003; 5: 19-26.

3. Warner HR: Apoptosis: a two-edged sword in aging. Ann N Y Acad Sci. 1999; 887: 1-11.

4. Higami Y, Shimokawa I: Apoptosis in the aging process. Cell Tissue Res. 2000; 301: 125-32.

5. Wyllie AH, Kerr JF, Currie AR: Cell death: the significance of apoptosis. Int Rev Cytol. 1980; 68: 251-306.

6. Warner HR, Hodes RJ, Pocinki K: What does cell death have to do with aging? J Am Geriatr Soc. 1997; 45: 1140-6.

7. Goodman M, Bostick RM, Dash C, Flanders WD, Mandel JS: Hypothesis: oxidative stress score as a combined measure of pro-oxidant and antioxidant exposures. Ann Epidemiol. 2007; 17: 394-9.

8. Zhang X, Zhang Q, Zhang Z, Na Y, Guo Y: Apoptosis profiles in benign prostatic hyperplasia: close associations of cell kinetics with percent area density of histologic composition. Urology. 2006; 68: 905-10.

9. Nunes VA, Gozzo AJ, Cruz-Silva I, Juliano MA, Viel TA, Godinho RO et al.: Vitamin E prevents cell death induced by mild oxidative stress in chicken skeletal muscle cells. Comp Biochem Physiol C Toxicol Pharmacol. 2005; 141: 225-40. 
10. Machlin LJ, Bendich A: Free radical tissue damage: protective role of antioxidant nutrients. FASEB J. 1987; 1: 441-5.

11. Bell EF: History of vitamin $E$ in infant nutrition. Am J Clin Nutr. 1987; 46(1 Suppl): 183-6.

12. Finkel T, Holbrook NJ: Oxidants, oxidative stress and the biology of ageing. Nature. 2000; 408: 239-47.

13. Dean RT, Fu S, Stocker R, Davies MJ: Biochemistry and pathology of radical-mediated protein oxidation. Biochem J. 1997; 324: 1-18.

14. Cabelof DC, Raffoul JJ, Ge Y, Van Remmen H, Matherly LH, Heydari AR: Age-related loss of the DNA repair response following exposure to oxidative stress. J Gerontol A Biol Sci Med Sci. 2006; 61: 427-34.

15. Cracowski JL, Durand T: Cardiovascular pharmacology and physiology of the isoprostanes. Fundam Clin Pharmacol. 2006; 20: 417-27.

16. Oner-lyidoğan $Y$, Koçak H, Gürdöl F, Koçak T, Erol B: Urine 8-isoprostane F2alpha concentrations in patients with neurogenic bladder due to spinal cord injury. Clin Chim Acta. 2004; 339: 43-7.

17. Kelâmi A: Treatment of morbus Peyronie--how I do it? Twenty years of experience. Int Urol Nephrol. 1991; 23: 589-93.

18. Sheweita SA, Tilmisany AM, Al-Sawaf $\mathrm{H}$ : Mechanisms of male infertility: role of antioxidants. Curr Drug Metab. 2005; 6: 495-501.
19. Parekh MH, Lobel R, O'Connor LJ, Leggett RE, Levin RM Protective effect of vitamin $E$ on the response of the rabbit bladder to partial outlet obstruction. J Urol. 2001; 166: 341-6.

20. Azzi A. The role of alpha-tocopherol in preventing disease. Eur J Nutr. 2004; (43 Suppl 1): I/18-25.

21. Reckelhoff JF, Kanji V, Racusen LC, Schmidt AM, Yan SD, Marrow $\mathrm{J}$ et al.: Vitamin $\mathrm{E}$ ameliorates enhanced renal lipid peroxidation and accumulation of F2-isoprostanes in aging kidneys. Am J Physiol. 1998; 274(3Pt2): R767-74.

22. Jara M, Carballada R, Esponda P. Age-induced apoptosis in the male genital tract of the mouse. Reproduction. 2004; 127: 359-66.

23. Banerjee PP, Banerjee S, Tilly KI, Tilly JL, Brown TR, Zirkin BR. Lobe-specific apoptotic cell death in rat prostate after androgen ablation by castration. Endocrinology. 1995; 136: 4368-76.

\section{Correspondence address:} Dr. Guilherme Fartes

Rua Capitão Luiz Soares, 535 São Paulo, SP, 11600-000, Brazil Fax: +55 11 3892-1062 E-mail: guifartes@hotmail.com 